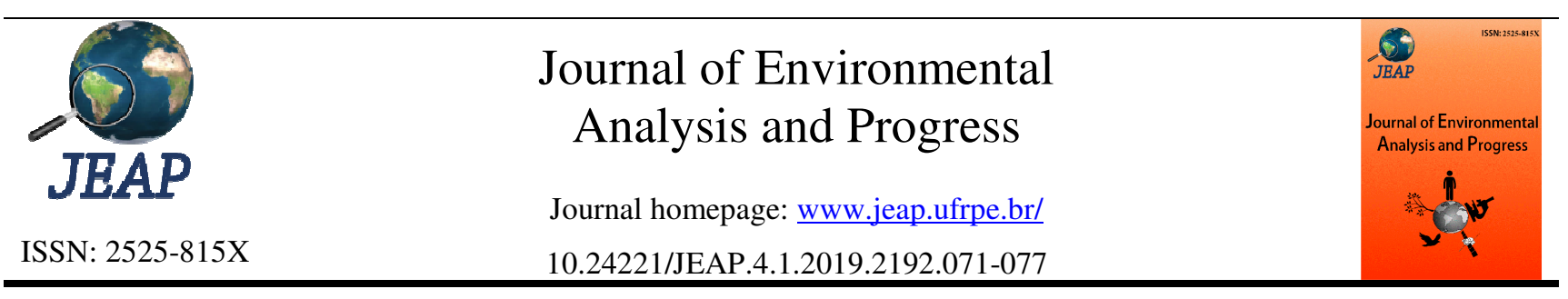

\title{
Parâmetros de qualidade da nata de produção artesanal
}

\section{Quality parameters of handcrafted production of nata}

Neide Kazue Sakugawa Shinohara ${ }^{\mathrm{a}}$, Indira Maria Estolano Macedo ${ }^{\mathrm{b}}$,Thaynna Leocádio Trajano Lacerda Sousa $^{\mathrm{b}}$, Rejane Magalhães de Mendonça Pimentel ${ }^{\mathrm{c}}$, Maria do Rosário de Fátima Padilha ${ }^{\mathrm{a}}$, Viviane Lansky Xavier ${ }^{\mathrm{d}}$, Isaura Botelho ${ }^{\mathrm{e}}$

${ }^{\text {a } U n i v e r s i d a d e ~ F e d e r a l ~ R u r a l ~ d e ~ P e r n a m b u c o-U F R P E, ~ D e p a r t a m e n t o ~ d e ~ T e c n o l o g i a ~ R u r a l, ~ L a b o r a t o ́ r i o ~ d e ~ A l i m e n t o s ~ e ~}$ Laboratório de Microbiologia Ambiental, Rua Dom Manoel de Medeiros, SN, Dois Irmãos, Recife, Pernambuco, Brasil. CEP: 52171-900. E-mail: neideshinohara@gmail.com, padilhamrf@gmail.com.

b UFRPE, Depto. de Economia Doméstica. E-mail: indiramacedo21@gmail.com; thaynna.leocadio0@gmail.com.

${ }^{c}$ UFRPE, Depto. de Biologia-Área de Botânica. E-mail: rejanemmpimentel@gmail.com.

${ }^{\mathrm{d}}$ UFPE, Depto. de Nutrição. E-mail: vivianelansky@yahoo.com.br.

e Universidade Federal da Bahia-UFBA, Fundação Joaquim Nabuco, Serviço Social do Comércio-SESC São Paulo. Email: zau.botelho@gmail.com.

\section{A R T I C L E I N F O}

Recebido 25 Out 2018

Aceito 29 Jan 2019

Publicado 31 Jan 2019

\begin{abstract}
A B S T R A C T
An important dairy basin located in the region of Agreste of Pernambuco, maintains the tradition in the production of milk and derivatives, having in the cream a lipid food of great sensorial appreciation. However, its artisanal production can compromise the physical-chemical and hygienic-sanitary quality. Therefore, this study aimed to evaluate the microbiological parameters and the centesimal composition of the cream produced in the Agreste of Pernambuco. Total coliforms at the mean concentration of $4.0 \times 10^{2} \mathrm{CFU}^{-1} \mathrm{~g}^{-1}$ and thermotolerant coliforms up to $20 \mathrm{CFU} . \mathrm{g}^{-1}$ were found, the latter in concentration above the limit allowed by RDC No. 12 (BRASIL, 2001). the amount of up to $10 \mathrm{CFU}^{-1}{ }^{-1}$, thus proving the presence of fecal material next to the product. The presence of coagulase positive Staphylococcus and Salmonella spp. The centesimal composition of the cream showed $531.07 \mathrm{kcal}, 39.39 \%$ humidity, $0.26 \mathrm{~g}$ ash, $0.92 \mathrm{~g}$ of carbohydrate, $1.7 \mathrm{~g}$ of protein, and $57.73 \mathrm{~g}$ of lipids. Considering the microbiological results and the centesimal composition, it is observed that the cream studied should be consumed with moderation, since besides presenting a high percentage of lipids, above the nutritional recommendation, that is up to $30 \%$, it is unsafe as to its consumption, due to the presence of thermotolerant coliforms above the limit allowed by current sanitary legislation.
\end{abstract}

Keywords: Milk derivative, milk lipid, milk microbiota.

\section{R E S U M O}

$\overline{\text { Importante bacia leiteira localizada na região do Agreste de Pernambuco, mantêm a }}$ tradição na produção de leite e derivados, tendo na nata um alimento lipídico de grande apreciação sensorial. Entretanto, sua produção artesanal pode comprometer a qualidade físico-químico e higiênico-sanitária. Portanto, essa pesquisa objetivou avaliar os parâmetros microbiológicos e da composição centesimal da nata produzida no Agreste de Pernambuco. Foram encontrados coliformes totais na concentração média de $4,0 \times 10^{2} \mathrm{UFC}_{\mathrm{g}} \mathrm{g}^{-1}$ e coliformes termotolerante até $20 \mathrm{UFC} \cdot \mathrm{g}^{-}$ 1, essa última na concentração acima do limite permitido pela legislação vigente, que estabelece até 10 UFC. $\mathrm{g}^{-1}$, comprovando a presença de material fecal junto ao produto. Não foram detectadas a presença de Staphylococcus coagulase positiva e Salmonella spp. A composição centesimal da nata apresentou 531,07 kcal; 39,39\% de umidade; 0,26 g cinzas; 0,92 g de carboidrato; $1,7 \mathrm{~g}$ de proteína e 57,73 g de lipídeos. Diante dos resultados microbiológicos e da composição centesimal, observa-se que a nata pesquisada deve ser consumida com moderação, pois além de 
apresentar alto percentual de lipídeos, acima da recomendação nutricional, que é de até $30 \%$, mostra-se inseguro quanto ao seu consumo, por apresentar coliformes termotolerantes acima do limite permitido na legislação sanitária vigente.

Palavras-Chave: Derivado de leite, lipídeo lácteo, microbiota do leite.

\section{Introdução}

O leite de diversos mamíferos é usado para a alimentação há mais de cinco mil anos na região da Mesopotâmia, no Oriente Médio. O leite bovino é rico em proteínas de valor biológico (caseína, $\quad \beta$ globulina, $\alpha$ globulina, imunoglobulinas e albumina), carboidrato (lactose), minerais (cálcio, selênio, zinco e magnésio) e vitaminas D, B12 (cobalamina) e B2 (riboflavina), sendo considerado um dos produtos mais completos quanto ao valor nutricional. É utilizado na dieta humana, em todas as faixas etárias, pois auxilia no desenvolvimento e crescimento, sendo um alimento essencial na vida de crianças, nos primeiro anos de vida (Ornelas, 2007; Silva et al., 2013).

Um derivado lácteo, a nata ou duplo creme, é obtido a partir do leite integral homogeneizado, que, após passar por processo mecânico de passagem por pequenos orifícios, resulta em pequenos glóbulos de gordura que se agregam formando a nata, uma emulsão de gordura em água. Essa forma de emulsão se apresenta mais estável e uniforme para a confecção de diferentes preparações culinárias, principalmente em molhos e produtos de confeitaria, que podem ser submetidos a altas temperaturas sem que ocorra a coagulação proteica (Borgo et al., 2014; Domene, 2011; Ornelas, 2007).

Segundo o Ministério da Agricultura, Pecuária e Abastecimento do Brasil (MAPA), a nata é o produto lácteo rico em gordura retirada do leite, que apresenta a forma de uma emulsão de gordura em água, homogeneizado ou não, e submetida a um processo de pasteurização, mediante tratamento térmico e procedimentos tecnologicamente adequados, suficientes para destruir parte dos microrganismos patogênicos (Brasil, 2012).

Os microrganismos presentes no leite cru são influenciados por fatores zootécnicos: manejo, alimentação, genética, idade do animal e aqueles relacionados com a obtenção do produto: biota encontrada no úbere, na pele, ou que entra em contato com o manipulador, através dos utensílios e equipamentos da ordenha. Mesmo que seja mantido sob refrigeração, o leite pode apresentar bactérias patogênicas dos grupos da família das Enterobacteriacea (Enterococcus, Escherichia coli e Salmonela spp.), assim como outros patógenos alimentares, como Clostridium spp., Bacillus spp. e Listeria monocytogenes (Franco \& Landgraf,
2005; Germano \& Germano, 2015; Jay, 2005; Soares et al., 2013).

O lipídeo no leite é a fração mais variável, sendo constituída por diferentes ácidos graxos e a proporção varia de acordo com a dieta ofertada ao animal e do estágio de lactação. Os ácidos graxos saturados correspondem a, aproximadamente, $70 \%$ do total, seguido de $27 \%$ de monoinsaturados e dienos e trienos, com 3,0\% (Borgo et al., 2014).

Segundo Claro et al. (2015), em levantamento do consumo de alimentos não saudáveis no Brasil, em 2013, o consumo mais preocupante diz respeito à grande prevalência de alimentos de fonte em gordura saturada, podendo evoluir para um aumento do risco de doenças crônicas não transmissíveis (DCNT) na população brasileira. Essa realidade representa perigo para o aumento dos fatores de risco cardiovascular em humanos.

A nata pode ser consumida in natura, mas também é indicada para preparações culinárias aquecidas, pois seu alto teor em lipídeos, cerca de $50 \%$ da composição, comprova sua propriedade química ao ser submetida a altas temperaturas, espessando as preparações, sem coagular com facilidade durante a cocção. Isso ocorre porque, com o aumento da temperatura, as moléculas de água se distanciam e ocorre a evaporação. Os glóbulos de gordura se aderem à caseína, formando uma camada protetora, impedindo a formação do coágulo desta proteína, que poderia resultar em coagulação do leite, alterando as preparações culinárias onde forem adicionadas (Araújo et al., 2011; McGee, 2011).

O conhecimento da composição de alimentos consumidos nas diferentes regiões do Brasil é um elemento básico para ações de orientação nutricional, baseadas em princípios de desenvolvimento local e diversificação da alimentação, em contraposição à massificação de uma dieta monótona e desequilibrada, considerando valores alimentares geográficos (TACO, 2011). Valores culturais na alimentação, como o uso da nata, confere sabor e consistência bastante agradável, estimulando seu uso.

A nata do leite bovino, quando produzida artesanalmente, pode apresentar falhas quanto a padronização na qualidade do produto, a qual está relacionada à presença de contaminantes microbiológicos (Brasil, 2001), valor calórico e composição centesimal (Brasil, 2011). O estudo objetivou a avaliação da contribuição do uso da nata do leite bovino em elevada ingestão de 
gorduras saturadas na alimentação diária, associada a um possível surto alimentar.

\section{Material e Métodos}

Área de estudo
O estudo foi realizado em um município com 14.313 habitantes (IBGE, 2017), distante 127 km de Recife, capital de Pernambuco, situado na região do Agreste pernambucano, localizado nas coordenadas geográficas Latitude: $7^{\circ} 44^{\prime} 45^{\prime \prime} \mathrm{S}$, Longitude: $\quad 35^{\circ} 42^{\prime} 18^{\prime \prime} \mathrm{O}$, Datum WGS-84, conforme observamos na Figura 1.

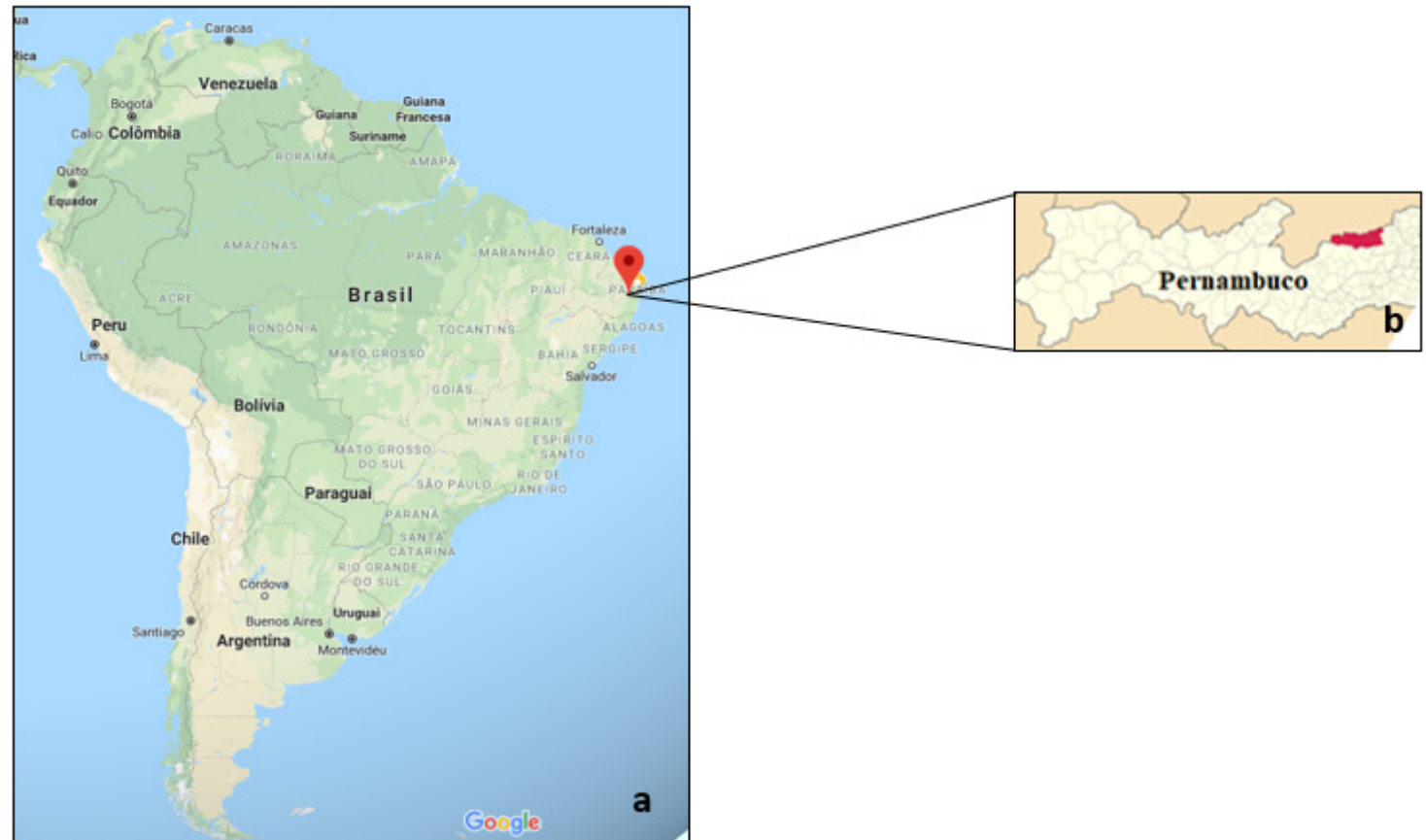

Figura 1. Localização da área de estudo no Brasil (a) e no Estado de Pernambuco (b), situado no Agreste pernambucano. Fonte: Google Maps (2019).

A pesquisa foi realizada no período de maio a julho de 2018, sendo adquiridas duas amostras de nata de leite bovino, acondicionadas em garrafas de pet de $500 \mathrm{~mL}$ de duas micro indústrias de produção local. A aquisição foi realizada na forma que o produto é comercializado na região do Agreste pernambucano.

As amostras foram conduzidas, em bolsas térmicas acompanhada de placas de gelo artificial, até o Laboratório de Alimentos do Departamento de Tecnologia Rural, da Universidade Federal Rural de Pernambuco.

Os ensaios microbiológicos e de composição centesimal foram iniciados no mesmo dia em que as amostras foram produzidas.

Para a contagem de coliformes totais e termotolerantes (Escherichia coli), Staphylococcus coagulase positiva e Salmonella spp. foram utilizados kits CompactDry®, respectivamente, CompactDry TC $®$, CompactDry EC®, CompactDryXSA®, CompactDry SL®, todas metodologias aprovadas pela Codex Alimentarius, I.C.M.S.F., APHA, FDA, ISSO Standards e AOAC para ensaios microbiológicos de alimentos. Posteriormente, foram confrontados os resultados obtidos das amostras de nata de leite com os parâmetros exigidos pela legislação vigente (Brasil, 2001).

Os ensaios foram realizados em duplicata e os resultados foram expressos em Unidade Formadora de Colônia por grama (UFC. $\mathrm{g}^{-1}$ ) para coliforme total, coliforme termotolerante e Staphylococcus coagulase positiva, para a detecção de Salmonela spp., os resultados foram expressos em presença/ausência em $25 \mathrm{~g}$ de amostra de nata de leite bovino, como descrito pela RDC n ${ }^{\circ} 12$ (Brasil, 2001).

$\mathrm{Na}$ avaliação da composição centesimal foram realizados ensaios físico-químicos para a determinação dos macro e micronutrientes, como proteínas, carboidratos, lipídeos, cinzas e umidade, seguindo metodologia descrita nas Normas Analíticas do Instituto Adolfo Lutz, em conformidade com a legislação em vigor (Brasil, 2012; IAL, 2008).

\section{Resultados}

Um produto semelhante ao creme de leite, a nata, produzida no Agreste pernambucano, é o que a indústria de alimentos classifica como creme de leite fresco, com teor de gordura variando de 36 a 40\% (Gisslen, 2012). 
A nata apresentou composição centesimal de acordo com o estabelecido na legislação (Tabela 1). No caso da nata em estudo, observouse que foi encontrada uma concentração média de 57,73\% de lipídeos (Tabela 1), determinada após aplicação de tecnologia de produção artesanal de pequenos produtores, que utiliza tachos de madeira com orifícios, para a separação dos glóbulos de gordura.
A Tabela 2 apresenta os resultados dos ensaios biológicos para a detecção de coliformes totais, obtendo-se uma média de 4,0 x $10^{2} \mathrm{UFC} \cdot \mathrm{g}^{-}$ 1 , termotolerantes com média de $20 \mathrm{UFC}^{-\mathrm{g}^{-1}}$, Staphylococcus coagulase positiva inferior a 10 UFC. $\mathrm{g}^{-1}$ e ausência para Salmonella spp. nas amostras analisadas.

Tabela 1. Valor calórico total, macro e micronutrientes de nata bovina in natura. Fonte: Shinohara (2018).

\begin{tabular}{|c|c|c|c|c|c|c|}
\hline Amostras de nata & kcal & Cinzas & Umidade & Carboidrato & Proteína & Lipídeo \\
\hline bovina in natura & $\%$ & g & $\%$ & & g & \\
\hline A1 & 530,29 & 0,27 & 39,32 & 0,98 & 1,7 & 57,73 \\
\hline A2 & 531,85 & 0,25 & 39,45 & 0,87 & 1,7 & 57,73 \\
\hline Média & $531,07 \pm 1,10$ & $0,26 \pm 0,01$ & $39,38 \pm 0,09$ & $0,92 \pm 0,07$ & $1,7 \pm 0,00$ & $57,73 \pm 0,00$ \\
\hline $\begin{array}{l}\text { Creme de Leite } \\
\text { (TACO, 2011) }\end{array}$ & 221 & 0,60 & 70,9 & 4,5 & 1,5 & 22,5 \\
\hline
\end{tabular}

Tabela 2. Análise bacteriológica da nata bovina in natura. SR = sem referência na legislação (Brasil, 2001). Fonte: Shinohara (2018).

\begin{tabular}{lcccc}
\hline Amostras de nata in natura & $\begin{array}{c}\text { Coliforme } \\
\text { total }\end{array}$ & $\begin{array}{c}\text { Coliforme } \\
\text { termotolerante }\end{array}$ & $\begin{array}{c}\text { Staphylococcus } \\
\text { coagulase positiva }\end{array}$ & Salmonella spp. \\
\hline A1 & $3,0 \times 10^{2}$ & 20 & $<10$ & Ausência \\
A2 & $5,0 \times 10^{2}$ & 20 & $<10$ & Ausência \\
Média & $4,0 \times 10^{2}$ & 20 & $<10$ & Ausência \\
\hline Tolerância para amostra & SR & 10 & $10^{2}$ & Ausência \\
indicativa (Brasil, 2001) & SR & & & \\
\hline
\end{tabular}

\section{Discussão}

O leite e seus derivados constituem um grupo de alimentos de grande valor nutricional, por serem fontes consideráveis de proteínas de alto valor biológico, além de fonte de vitaminas e sais minerais. O consumo habitual destes alimentos é recomendado, principalmente, para atingir a adequação diária de cálcio, um nutriente fundamental para a formação e a manutenção da estrutura óssea, entre outras funções no organismo (Muniz, Madruga \& Araújo, 2013; Sizer \& Whitney, 2003).

Em relação ao creme de leite, sua época de ouro foi no século XVIII, quando usado em bolos, pudins, sorvetes e pratos de intenso sabor, como fricassês - cozido de carne e hortaliças - e molho beurre blanc. A partir do Século XX, devido à recomendação dietética para evitar o consumo de gorduras saturadas, sua popularidade e pluralidade de uso foram sendo substituídas, tendo em vista seu alto percentual de gordura saturada (Batalha \& Bessa, 2018; McGee, 2011).

Conhecer a composição do leite e os padrões de sua qualidade são fatores necessários para a adequada promoção da saúde humana, visto que a ausência desses parâmetros de controle pode propiciar a ingestão de substâncias contaminantes, derivadas de falhas nos diferentes processos na cadeia de produção do leite (Silva et al., 2015).

As informações presentes em uma tabela de composição de alimentos (TACO, 2011) são pilares básicos para promover uma adequada educação nutricional, um controle da qualidade dos alimentos e a avaliação da ingestão de nutrientes de indivíduos ou populações. Através da aplicação dos valores dos itens dessa tabela, as autoridades de saúde pública podem estabelecer metas nutricionais e guias alimentares que auxiliam na aplicação de uma dieta mais saudável para a população (TACO, 2011).

$\mathrm{O}$ leite integral contém quantidades aproximadamente iguais de proteína e lipídeos. No caso da nata, a quantidade de gordura supera a de proteínas, com uma relação de 10 partes de lipídeos para 1 parte de proteína. Devido a essa relação da proteína com o lipídeo, a nata tende menos a coagular, porque o lipídeo forma uma camada de proteção para evitar a coagulação proteica, frente à cocção (McGee, 2011). Entretanto, neste estudo, a concentração de lipídeo superou a de proteína em cerca de 33 vezes. Em consequência, a alta concentração de lipídeos na nata dificulta a coagulação e, por este motivo, esse 
produto é muito utilizado na culinária pernambucana como espessante e saborizante.

Uma das aplicações culinárias da nata em diferentes culturas gastronômicas, perfeitamente fundamentada, é a sua utilização como agente de textura, aumentando a viscosidade, o brilho e o sabor em molhos, caldos, produtos de panificação e confeitaria, na preparação do molho francês mornay, com a indicação de acompanhamento de peixes; no Sudeste brasileiro, os famosos biscoitos de nata, e no nordeste brasileiro, como acompanhamento de comidas juninas, como pamonha, milho e mungunzá (Batalha \& Bessa, 2018; Freixa \& Chaves, 2017).

Segundo a Tabela Brasileira de Composição de Alimentos (TACO, 2011), o creme de leite é o derivado lácteo mais semelhante à nata pernambucana, e possui em cada 100 g: $70.9 \%$ de umidade; $221 \mathrm{kcal} ; 1,5 \mathrm{~g}$ proteína; 22,5 $\mathrm{g}$ de lipídeo; $4,5 \mathrm{~g}$ de carboidratos e $0,6 \mathrm{~g}$ de cinzas. Por se tratar de um produto de origem animal, segundo a TACO (2001), os ácidos graxos presentes no creme de leite estão na proporção de $11,8 \mathrm{~g}$ de saturados; $5,1 \mathrm{~g}$ de monoinsaturado e $0,5 \mathrm{~g}$ de poli-insaturados.

Resultado semelhante foi encontrado apenas para proteína $\left(1,7 \mathrm{~g} .100 \mathrm{~g}^{-1}\right)$, conforme observado na Tabela 1, quando comparado com os dados da TACO (2011). Nessa tabela de composição de alimentos foi encontrado um valor de $1,5 \mathrm{~g} \cdot 100 \mathrm{~g}^{-1}$, diferindo para calorias, umidade, lipídeos, carboidratos e cinzas. Vale salientar que o teor de lipídeos na nata é muito superior $(531,07$ g. $\left.100 \mathrm{~g}^{-1}\right)$ quando comparado àquele encontrado no creme de leite $\left(22,5\right.$ g. $\left.100 \mathrm{~g}^{-1}\right)$. Entretanto, quando se observam os carboidratos presentes no creme de leite, o valor é de 4,5 g. $100 \mathrm{~g}^{-1}$ e na nata é de 0,926 g. $100 \mathrm{~g}^{-1}$. Portanto, a nata de leite investigada é rica em lipídeos, especificamente de ácido graxo saturado, e o creme de leite é superior em percentual de carboidrato.

O consumo de gordura saturada é classicamente relacionado com a elevação do LDL-c plasmático e aumento de risco cardiovascular. A substituição de gordura saturada da dieta por mono e poli-insaturada é considerada uma estratégia para o melhor controle da hipercolerestemia e, consequente redução da chance de eventos clínicos, como hipertensão arterial sistêmica, diabetes mellitus e obesidade (Santos et al., 2013; Sizer \& Whitney, 2003). Diante dessa informação sobre a gordura saturada, a nata de leite deve ser consumida com precaução, devido à alta concentração desta gordura em sua composição.

Em outro estudo promovido por Padilha \& Shinohara (2016), a análise da composição centesimal da nata, produzida e comercializada no Agreste de Pernambuco, mostra que este é um produto extremamente calórico e de alto conteúdo de gordura animal saturada. No entanto, se houver uma boa orientação para a sua produção sob condições adequadas, em obediência às Boas Práticas de Produção (BPP) e orientações seguras de consumo, o mesmo se mostra como um produto natural, pois pode ser um substituto de manteiga, margarina, requeijão e creme de leite, entre outros derivados lácteos.

Apesar de ser apreciada, desde os primórdios da extração do leite, a nata mostra uma deterioração microbiana mais rápida, comparando com a manteiga, devido a ação de microrganismos psicotróficos e lipolíticos (Franco \& Landgraf, 2005; Jay, 2005). Os psicotróficos $\left(0^{\circ} \mathrm{C}-10^{\circ} \mathrm{C}\right)$ geram muitos problemas para os alimentos conservados em cadeia de frio, como carnes e leites, principalmente por esse grupo de microrganismos apresentar a capacidade de produzir enzimas proteolíticas e lipolíticas (Azeredo, 2012). Esse grupo tem como representantes as Pseudomonas, Lactobacillus e Listeria monocytogenes; algumas cepas de Salmonella spp. podem também proliferar no leite refrigerado (Tondo \& Bartz, 2012).

Os resultados encontrados para a detecção de coliformes totais e termotolerantes, Staphylococcus coagulase positiva e Salmonella spp. (Tabela 2), foram os parâmetros investigados, baseados na determinação da Resolução de Diretoria Colegiada da ANVISA, RDC $\mathrm{n}^{\circ} .12$ (Brasil, 2001). A exceção dessa legislação sanitária foi a investigação de coliformes totais, visto que não existe como obrigatoriedade legal quanto à detecção desse parâmetro biológico, entretanto, é considerado um importante parâmetro sanitário (Silva Júnior, 2014, Silva et al., 2015).

Apesar de não haver um parâmetro na legislação em vigor quanto a obrigatoriedade na avaliação de coliforme total, para atestar conformidade sanitária no país, segundo Kim et al. (2017), a pesquisa dos coliformes totais é importante. Isto se justifica porque a sua ausência é considerada um indicador biológico de higiene do ambiente. São úteis para identificar se as boas práticas são implementadas, bem como para mostrar alguma possível presença de enteropatógenos, uma vez que pode estar associada com a microbiota entérica, oriunda de contaminação cruzada.

A contagem de coliformes termotolerantes está acima de valores permitidos como referência, conforme a RDC $\mathrm{n}^{\circ} .12$ (Brasil, 2001), onde o limite máximo é de 10 UFC.g ${ }^{-1}$ de nata. Segundo 
Franco \& Landgraf (2005), Franco (2012) e Jay (2005), esse patógeno faz parte da microbiota natural do conteúdo intestinal dos seres humanos e dos animais de sangue quente; quando presente nos alimentos indica contaminação de origem fecal, podendo causar graves surtos de grande repercussão na saúde pública.

A transmissão dos coliformes termotolerantes ocorre normalmente através da rota fecal/oral, por meio de água e alimentos contaminados que servem de veiculação desse patógeno entérico. A intoxicação alimentar de origem bacteriana frequentemente ocorre nos produtos lácteos, quando a matéria prima está comprometida, ou não é corretamente manipulada e acondicionada, sem o uso de refrigeração e embalagem adequadas. Portanto, a melhor forma de prevenir a presença dos coliformes totais e termotolerantes é o cuidado na seleção da matériaprima, na cadeia de produção e na conservação posterior do leite, para evitar surtos de origem biológica (Harvey, Champe, Fisher \& 2008; Silva Júnior, 2014).

Neste estudo, as amostras não apresentaram contaminação por Staphylococcus coagulase positiva e Salmonella spp; ; este fato mostrou ser um indicativo de que a produção pode não ser a origem da interferência/contaminação através do manipulador. Entretanto, o monitoramento constante deve ser permanente para a garantia da segurança na cadeia de produção de alimentos, o que, segundo a literatura, objetiva minimizar os agravos à saúde do consumidor (Ayçiçek, 2004; Germano \& Germano, 2015).

\section{Conclusão}

A ingestão constante e acentuada de nata do leite bovino na alimentação humana promove um elevado risco biológico e nutricional, quanto ao consumo acima da recomendação dietética, pois o valor microbiológico encontrado para os coliformes termotolerantes está superior ao exigido pela Legislação, o que é um indicativo de contaminação de origem fecal.

\section{Referências}

AOAC. 2005. Official methods of analysis of the Association Analytical Chemists. $18^{\mathrm{a}}$ ed. Gaithersburg, Maryland.

APHA. 2005. Standard methods for the examination of water and wastewater, 21sted. Washington, DC, New York: American Public Health Association.
ARAÚJO, W. M. C.; MONTEBELlO, N. P.; BOTELHO, R. B. A.; BORGO, L. A. (Org.). 2011. Alquimia dos Alimentos. Brasília: Senac.

AYÇIÇEK, $\quad$ H.; $\quad$ AYDOĞAN, $\quad$ H.; KÜÇÜKKARAASLAN, A.; BAYSALLAR, M.; BAŞUSTAOĞLU, A. C. 2004. Assessment of the Bacterial Contamination of hands of hospital food handlers. Food Control, v. 15, p. 253-259.

BATALHA, A. S.; BESSA, R. M. R. 2018. Termos da gastronomia francesa utilizados na gastronomia brasileira na categoria dos molhos. Revista Non Plus, v. 6, n. 11, p. 168-177.

BORGO, L. A.; MONTEBELO, N. P.; BOTELHO, R. B. A.; ARAÚJO, W. M. C. 2014. Alquimia dos Alimentos. Brasília: Senac.

BRASIL. 2001. Ministério da Saúde. Agência Nacional de Vigilância Sanitária (ANVISA). Resolução RDC $\mathrm{n}^{\circ} 12$ de 02 de janeiro de 2001. Regulamento Técnico Sobre os Padrões Microbiológicos para Alimentos. Diário Oficial. Brasília, DF. 10 de janeiro de 2001.

BRASIL. Instrução Normativa $n^{\circ} 23$, de 30 de agosto de 2012. Regulamento fixa a identidade e os requisitos mínimos de qualidade que deverá ter a nata destinada ao consumo humano. Brasília, DF: Ministério da Agricultura, Secretaria de Inspeção de Produto Animal.

CLARO, R. M.; SANTOS, M. A. S.; OLIVEIRA, T. P.; PEREIRA, C. A.; SZWARCWALD, C. L.; MALTA, D. C. 2015. Consumo de alimentos não saudáveis relacionados a doenças crônicas não transmissíveis no Brasil: Pesquisa Nacional de Saúde, 2013. Epidemiologia e Serviços de Saúde, v. 24, p. 257-265.

DOMENE, S. M. A. 2011. Técnica Dietética: teoria e aplicações. Rio de Janeiro: Guanabara Koogan.

FRANCO, B. D. G. M.; LANDGRAF, M. 2005. Microbiologia dos Alimentos. São Paulo: Atheneu.

FRANCO, R. M. 2012. Agentes Etiológicos de Doenças Alimentares. Niterói: Editora UFF.

FREIXA, D.; CHAVES,G. 2017. Gastronomia no Brasil e no Mundo. São Paulo: SENAC. 
GERMANO, P. M. L.; GERMANO, M. I. S. 2015. Higiene e Vigilância Sanitária de Alimentos. São Paulo: Manole.

GISSLEN, W. 2012. Culinária Profissional. São Paulo: Manole.

HARVEY, R. A.; CHAMPE, P. C.; FISHER, B. D. 2008. Microbiologia Ilustrada. Porto Alegre: Artmed.

IAL. 2008. Instituto Adolfo Lutz (São Paulo). Normas Analíticas do Instituto Adolfo Lutz. Métodos Químicos e Físicos para Análise de Alimentos. $4^{\mathrm{a}}$ Edição, $1^{\mathrm{a}}$ Edição digital, São Paulo: 1020p.

IBGE. Instituto Brasileiro de Geografia e Estatística. 2017. Disponível em: https://cidades.ibge.gov.br/brasil/pe/casinhas/pano rama. Acesso em: 15 de novembro de 2018.

ICMSF. 2002. Internetional Commission on Microbiological Specifications for Foods, 2002. Microrganisms in Food 7. Micobiological Testing in Food Safty Management. Kluwer Academic/ Plenum Publishers, New York.

JAY, J. M. 2005. Microbiologia de Alimentos. Porto Alegre: Artmed.

KIM, H. W.; HONG, Y. J.; JO, J. I.; HA, S. D.; KIM, S. H.; LEE, H. J.; RHEE, M. S. 2017. Raw ready-to-eat seafood safety: microbiological quality of the various seafood species available in fishery, hyper and online markets. Letters in Applied Microbiology, v. 64, n. 1, p. 27-34.

MAZIERO, M. T.; VIANA, C.; BERSOT, L. S. 2010. Microrganismos psicríficos lipolíticos em produtos lácteos durante o prazo comercial. Revista inst. Latic. Cândido Tostes, v. 65, n. 372, p. 10-17.

MCGEE, H. 2011. Comida \& Cozinha: Ciência e Cultura da Culinária. São Paulo: Martins Fontes.
MUNIZ, L. C.; MADRUGA, S. W.; ARAÚJO, C. L. 2013. Consumo de leite e derivados entre adultos e idosos no Sul do Brasil: um estudo de base populacional. Ciência \& Saúde Coletiva, v. 18 , p. 3515-3522.

ORNELAS, L. H. 2007. Técnica Dietética: Seleção e preparo de alimentos. São Paulo: Atheneu.

PADILHA, M. R. F.; SHINOHARA, N. K. S. 2016. Levantamento Cartográfico da Gastronomia como Equipamento Urbano nos Municípios Pernambucanosde Casinhas e Agrestina. Trabalho de Conclusão de Curso apresentado como requisito parcial para obtenção do Certificado do Curso de Aperfeiçoamento em Gestão Cultural.

SANTOS, R. D. et al. 2013. I Diretriz sobre o consumo de gorduras e saúde cardiovascular. Arquivos Brasileiros de Cardiologia, v. 100, n. 1, p 1-49.

SILVA JÚNIOR, E. A. 2014. Manual de Controle Higiênico-sanitário em Serviços de Alimentação.São Paulo: Varela.

SILVA, P. A. S.; SILVA, J. A. C.; COELHO, P. O.; SILVA JÚNIOR, E. 2015. Qualidade do leite uht comercializado em campos gerais, MG. Revista da Universidade Vale do Rio Verde, v. 13, n. 2, p. 415-423.

SIZER, F.; WHITNEY, E. 2003. Nutrição: Conceitos e Controvérsias. São Paulo: Manole.

SOARES, K. M. P.; GÓIS, V. A.; SILVA, J. B. A.; BEZERRA, N. M. 2013. Qualidade do creme de leite artesanal. Semina: Ciências Agrárias, v. 34 , n. 6, p. 2937-2944.

TACO. 2011. Tabela Brasileira de Composição de Alimentos/NEPA-UNICAMP. 4. edição revisada e ampliada, Campinas/SP.

TONDO, E. C.; BARTZ, S. 2012. Microbiologia e Sistema de Gestão da Segurança de Alimentos. Porto Alegre: Sulina. 